\title{
THE USAGE OF VUE JS FRAMEWORK FOR WEB APPLICATION CREATION
}

\section{Szerzők:}

Pšenák Peter

Comenius University in Bratislava (Slovakia)

Tibenský Matúš

Slovak University of Technology (Slovakia)

Első szerző e-mail címe:

peter.psenak@fm.uniba.sk

\section{Lektorok:}

\author{
Szabó Tibor (PhD) \\ Constantine the Philosopher University \\ in Nitra (Slovakia) \\ Szabóné Dr. Balogh Ágota (PhD) \\ Gál Ferenc Egyetem
}

...és további két anonim lektor

\section{Absztrakt \\ A VUE JS KERETRENDSZER HASZNÁLATA \\ WEB ALKALMAZÁS LÉTREHOZÁS ÁHOZ}

A tanulmány a front-end keretrendszerek pozitív oldalaira koncentrál. Létrehoz egy kis weboldalt, amely bemutatja a Vue JS nevü JavaScript front-end keretrendszer néhány alapvető képességét és megvalósításának egyszerűségét. Megmutatja, miért van szükség keretekre a fejlesztésben, valamint, hogy a vállalatok hogyan tudják a javukra fordítani a felhasználását. Mivel felhasználhatók és felgyorsítják a fejlesztési folyamatokat, az iskolákban megtanulhatók a fejlesztési koncepciók könnyebb megértése érdekében.

Kulcsszavak: Vue JS, Javascript, keretrendszerek, weboldalak, informatika

Diszciplinák: informatika, pedagógia

\begin{abstract}
The paper concentrates on the positive sides of front-end frameworks. It creates a small webpage that will show some of the basic capabilities of a JavaScript front-end framework called Vue JS and the easiness of its implementation. It shows why is there a need for frameworks in development and how can companies use them for their benefit. Since they can be used and speed up development processes they can be learned in schools for an easier grasp of development concepts.
\end{abstract}

Keywords: Vue JS, Javascript, frameworks, websites, information technology

Disciplines: Informatics, Pedagogy 
Pšenák Peter és Tibenský Matúš (2020): The usage of Vue JS framework for web application creation. Mesterséges intelligencia - interdiszciplináris folyóirat, II. évf. 2020/2. szám. 61-72. doi: 10.35406/MI.2020.2.61

The aim of this work is to show the positive sides of front-end frameworks on the process of learning web development through a small and quick application that we create in this article. We introduce why there is a need for an online presence and why would every organization want to have it. Then we discuss the actual development of web applications. First, we show the differences between web sites and web applications. Then, we discuss why is a software development framework needed at all and how can it help us in development, security, architecture and the actual learning process of application development. In this part we will discuss frameworks in general but then our article will solely concentrate on JavaScript frameworks. Furthermore, we analyze the top 3 most used JavaScript framework nowadays and choose one, which we use in the last chapter of the article during web application creation. The decision is made on the base of our experiences and different articles as well. One of the most important aspects of the article is the speed of learning the framework and the ability to use it as quickly as possible on a professional level. Furthermore, we want to show why companies would like to use frameworks during development and what positives can they gather from them.
Therefore, we also deal with the company point of view. At the end of our article, we create a small web application only for purposes of the framework syntax introduction and as a practical demonstration of how it works.

\section{Creation of web applications}

During the last decades, since the invention of the modern computers and the internet especially we see a high growth of their usage in our everyday life (Figure 1).

The usage of internet is still growing really fast, and in fact it grew by more than 2 billion worldwide since 2005. It is almost over half of the entire world population.

Figure 1: Number of internet users worldwide from 2005 to 2018 (in millions). Source: bttps:/ / www.statista.com/ statistics/273018/ numb er-of-internet-users-worldwide/

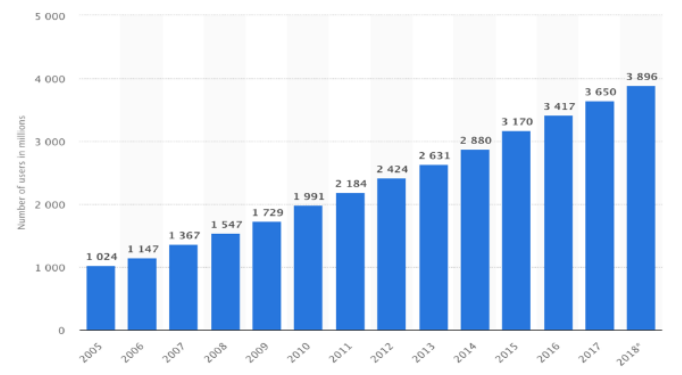


This grow of users has changed our everyday life completely. Most of us use google to find nearly any information we need, we go to Facebook to talk with our friends or to organize events, we use Instagram to share our pictures and daily stories etc. The amount of data on the internet is growing exponentially.

These changes created a wave in the global economy as well. Different companies had to adjust themselves to this change. They created departments which are only dealing with informational technologies.

These days most companies do have a website or a web application on which customers, or general audience can check every news they publish. They are using their online presence for a multitude of purposes. These applications need to be up to date all the time, because anyone can check them anytime, they want. For this reason, the knowledge to create or administer a website or web application is a really useful skill to master with the expectation to be so in the future.

\section{Need of websites}

The most straightforward way to create the above-mentioned online presence, is to buy a domain name and create a website or web application. Then upload the created files to a server and you can start sharing any type of information you would like. For some simple website is a good enough option. For others however, a web application should be a better way.

\section{Websites VS. Web Apps}

In our paper we do not use website and web application (web app) interchangeable. The reason for it is, that these are two different things even if for a normal user the difference might seem unnoticeable (Figure 2). A website is a static page mostly. Which means, that you find some information on them, for example general information of the company, then maybe a contact form for sending emails.

It doesn't mean that they do not contain links and cannot be multi paged. But generally, the user of those sites is just a passive information taker without the ability to manage the seen data or to work with them. Examples are: Blogs or most News websites.

Figure 2: Website and Web App difference. Source: https:// www.scnsoft.com/blog/webapplication-vs-website-finally-answered

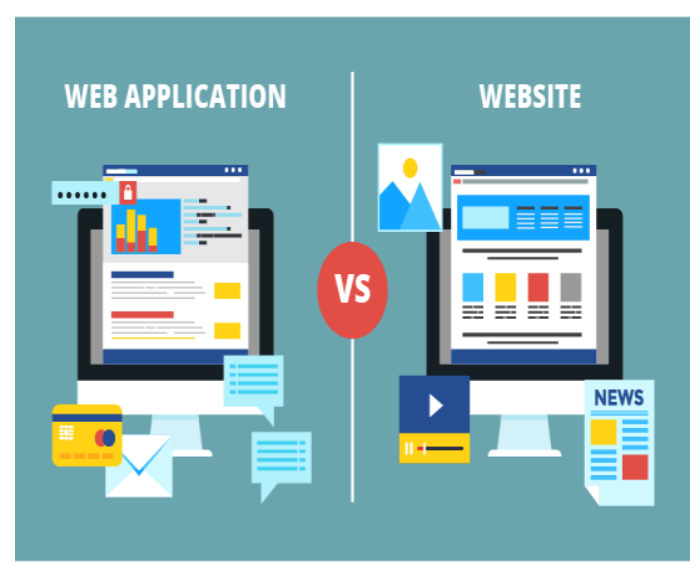


A web app on the other hand can be used for much more than for viewing only. They as well give information, but the user can sometimes even manipulate the data which they see. As an example, a local bookshop web app lets you search between the books the shop has. Most of e-shops are web applications as well (Cody Landefeld, 2016).

For most companies the difference comes in the developer needs they have. Not all developers have the same skillset hence you need to find those which are able to create a website or web app which you need. For the goal of this paper we will work only with web application. The reason for it is the wide usage in any type of organizations for example ecommerce. Next, we check the most used frameworks which are used for application creation.

\section{What is a framework and how can it help us? \\ Companies normally spends between 4 to} $6 \%$ of their revenues in IT departments (Morley, 2015). This huge amount of cash allocated stems in part from the long period of time which a software development takes. Creating a professional web app contains lot of repetitive activities and have a huge demand on software developers. The repetitive activities can be abstracted out into a framework hence for easier creation of both websites and web apps different web developer frameworks were created.
From a company point of view a framework is a great tool as well. Nowadays more IT departments are trying to find a better application architecture type to fit their needs. One of the most prevalent nowadays is the software as service (SOA).

SOA is an paradigm which concentrates around organizing and utilizing distributed capabilities which then may be under control of different ownership domains. In short it looks on a parts of an application as standalone services which communicate together to fit the needs of the organization (Natalia Kryvinska and Michal Greguš, 2014).

It adds value for the companies in multitude of aspects. They make develop-ment cycles faster, with shortening them. The loose coupling between the different part of the application helps in maintainability. Different services can be reused in different situations and much more (Michal Greguš and Natalia Ktyvinska, 2015). Modern frameworks make it easier to achieve SOA architecture because a software framework is a universal, reusable software creation environment in which a developer works (Figure 3).

Deploying an application in SOA architecture is not cheap (Kryvinska et al., 2011), however frameworks can help in achieving in with less costs.

Another Major point of view for a company is the informational security. There is a multitude of different types of attacks for example XSS (Cross Site cripting) or SQL injection (Szabó Tibor and Pšenáková Ildikó, 2011). The creators of frameworks think about these types of issues and make sure to 
Figure 3: What is a software framework, Source: https: / / www.youtube.com / watch? $v=j H H T I j x-$ $\underline{U O Q}$

\section{SOFTWARE FRAMEWORK}

\section{Sets of libraries or classes}

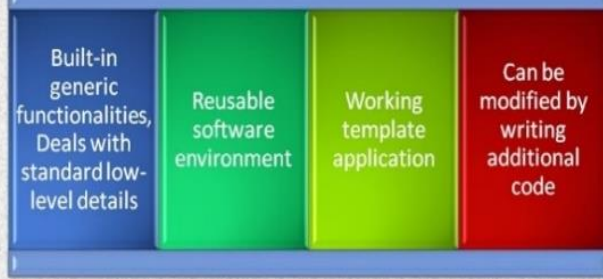

have security measures inside the frameworks as well which in turn creates lesser need for developers to work keep it safe.

A framework provides a standard way to build and deploy applications if we look on it from the software point of view. They are generally considered in modern software development, to make software creation faster and less error prone. Technically you do not need to use a framework to create web apps, however in most cases the developer professionals use it for speeding up their work (Margaret Rouse, 2015).

We will consider only JavaScript frameworks in this paper, however there are well known frameworks for web development in Python, PHP and other programming languages as well. The most used JavaScript frameworks for web applications are: Vue JS,
Angular, React (Neagoie, 2018). All of them are beloved by developers and used by many as it is shown on Figure 4 below.

Figure 4: Number of stars on frameworks given by developers- https:// medium.com/zerotomastery/techtrends-showdown-react-vs-angular-vs-vue-

\section{$\underline{61 f f a f 1 d 8706}$}

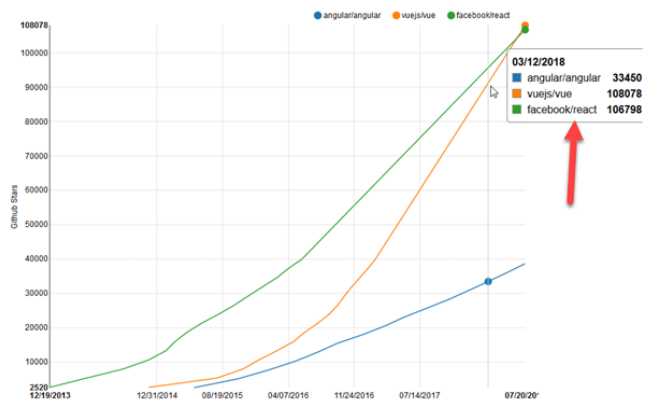

React is a JavaScript library for building web applications. It was developed and is maintained by Facebook. React is used by Facebook, Uber, Netflix, Twitter, Udemy, Paypal, and many more.

Angular is a framework created and maintained by Google. The best-known companies using it are Google, Forbes, WhatsApp, Instagram, and many more.

Vue.js is the newest from the three mentioned frameworks and is one of the most rapidly growing frameworks.

It was created by then Google employee Evan You. One of its biggest attractiveness stems from the ability to create user interfaces (UI) using HTML (hypertext markup language), CSS (cascading style sheet), and 
JavaScript. The framework is most notably used by Alibaba, GitLab, Baidu, 9GAG, and is appreciated by developers and designers globally (Ankit Kumar, 2018).

There is a huge amount of written material on the internet, which sole purpose is to find the "best" one between them. For example, react was the most beloved library in 2018 (Neagoie, 2018). However, as the time passed Vue JS is shown to be a strong competitor. The environment is changing so fast, that in 2019 Vue JS is competing mostly with React and in fact it has already overtaken it in some aspects (Codeburst, 2019). Most of the time it just comes down to personal preferences or company decision since the mentioned environment changes.

\section{Why we chose Vue JS?}

We chose Vue JS in our paper mostly because from our perspective it is the most user-friendly environment to use. It is really easy to start learning web development with Vue JS hence we can use it for teaching purposes. However, there are different positive things about it for example:

1. A great Command Line Installer (CLI) tool packed with Vue

2. Speed

3. Official packages like Vuex and Vue Router

4. Single file components

5. Lightweight

6. Great and easy to understand documentation

7. Can be progressively adopted into webpage(Bover, 2018)
What exactly is Vue JS? We can find the answer in the Official Documentation: "Vue is a progressive framework for building user interfaces. Unlike other monolithic frameworks, Vue is designed from the ground up to be incrementally adoptable. The core library is focused on the view layer only and is easy to pick up and integrate with other libraries or existing projects."

In core they say that Vue is an incrementally adoptable framework.

This means, that you can slowly integrate it into existing webpages. It is a great feature, because you can slowly integrate it and still keep your old webpage working therefore companies with already done websites can consider it as a future update.

However we still do not know how does this framework called Vue JS work and what exactly is it going to do for us and for our development.

\section{How does Vue JS work?}

Vue Js comes with a reactivity system (You, 2019). As a first step you create a Vue instance. During the instantiation of Vue you create some properties. When you define a data property (specific property of the Vue object) Vue creates getters and setters for it. These are JavaScript functions bound to a JavaScript object, which purpose is to dynamically return a computed value and to find changes dynamically of a specified property.

This system in general is then looking on changes in different properties of the website 
through getters and setters and depending on the changes it repaints the view on the places where it is needed. He does it through watchers, which are created behind the scenes as well.

We see the process on the Figure 5. as well. Rendering is the "repainting" process and virtual DOM (Document Object Model general document in which every website is created) is an Object created in JavaScript which copies the real DOM to see the changes on data.

Figure 5: Vue JS reactivity. Source: https:/ / vuejs.org/v2/guide/ reactivity.htmlm

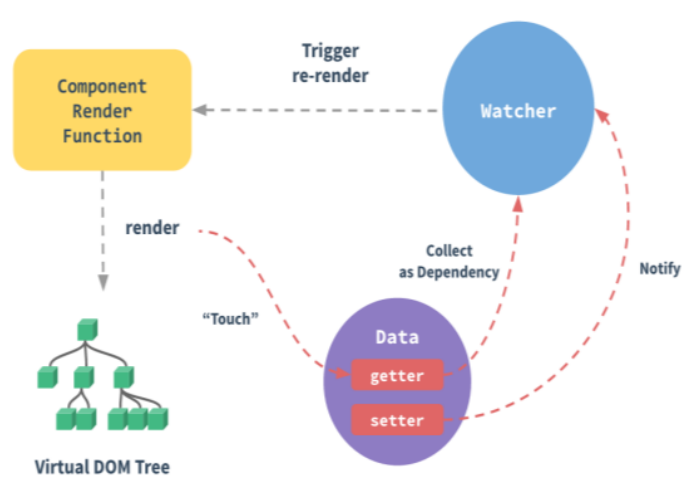

With this feature Vue JS created an environment for us in which we can abstract from a lot of code (which is written for us) and a bunch of basic development errors (which are solved for us behind the scenes in the framework). Therefore, the learning curve for a beginner is not that harsh as if somebody would have tried to learn pure JavaScript.

\section{Creation of a small page with vue}

Now we are going to build a small and easy Vue JS application. We will create a small app which will consists of an input and a button inside a small box. If the user starts to write inside the input, it will in real time show the text written inside of it on the bottom of the box. If the user clicks on the button it will show every letter of the written text inside the input alone. This may seem like a redundant functionality, however if we would show a registration form for the user and make him write his first and last name, he can possibly see the full name created in front of him in real time without the need of writing it again.

We will show the process of creating a Vue JS Object and then we add some of the most used basic features of the framework. With these features we show the general concept of the framework and we will show how it works.

We will use Codepen (https://codepen.io) as a tool for our small app. Codepen is an online tool in which we can write HTML, CSS and JavaScript, then show it on a page right away. It is used by front-end developers for trying out fast ideas, or sometimes to share full codes (called Pens in codepen) with others. First, we create a new pen from the menu and then, we can start with the setup.

First, we need to set up the tool for using Vue, so we import it. In the settings tab we choose a JavaScript package namely Vue JS. It will look like Figure 6.

We will concentrate on the HTML and JavaScript mostly however we will show the specific SCSS (a preprocessor which takes, 
Figure 6: Setting up VueJS in Codepen. Personal collection

\section{Add External Scripts/Pens}

Any URts added here will be added as sacriptos in order, and nun berore the Jwascriest in the edter. You can une the URL of any cther Pen and it wil include the Irabcriot from that inen

Q Search CDNis (Vuery, Lodash, React, Angular, Wue.js, Ember..)

Powered by Depla

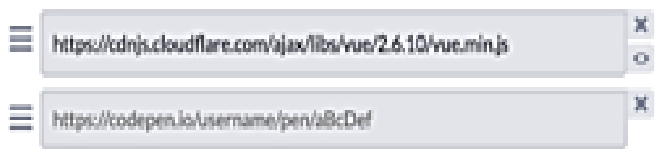

isd ansther reliource

and processes code written in SCSS and gives native CSS back) as well. We use SCSS because we like the syntax and the added options more than the native CSS. It again comes down to personal preferences if you use it or not. Now let's create a div tag with the id of app. Here we will create our Vue application. It will be bound to the id of app. Further we add a main tag inside of it and a section tag. These basic tags added are for the sole reason of easier styling and layout creation (Figure 7).

We now add a bit of styling and then we continue with the app. We won't deeply describe what does the styling do because it is not that important for us. In core it just sets the position of the elements to be centered, adds some width and height and some colors to the texts and background (Figure 8).

This will make it possible for us to make the whole application more visual and to see where and what we will change in the future more easily.
Figure 7: Basic HTML layout. Personal collection

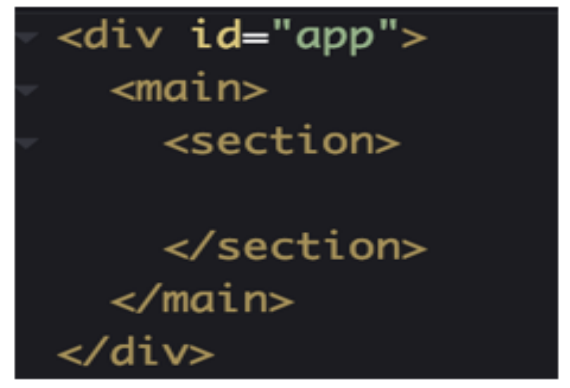

Figure 8: Basic styling. Personal collection

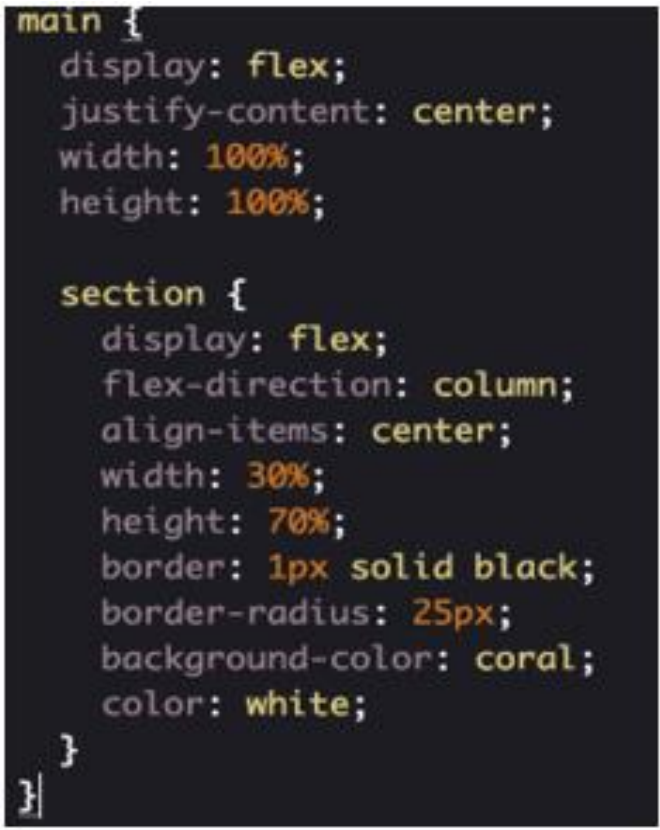

Now we will create a new Vue Object and inside of it we create a property of el. The name of the property must be el since we are actually creating a Vue instance and actually just adding the options into it. Inside this property we need to write the selector, which 
tells to Vue where it should be created. This means that Vue will look into our HTML and find the specific element. We write \#app, which means that we selected the id with value app (Figure 9). As a convention in HTML id must be a unique value, therefore we must be sure that there will not be more HTML tags with the id of app. We create a data property as well, in which we describe every type of data needed in our project. This data will be then managed by Vue during our interaction with the web app.

Figure 9: Basic Vue Object with data properties. Personal collection

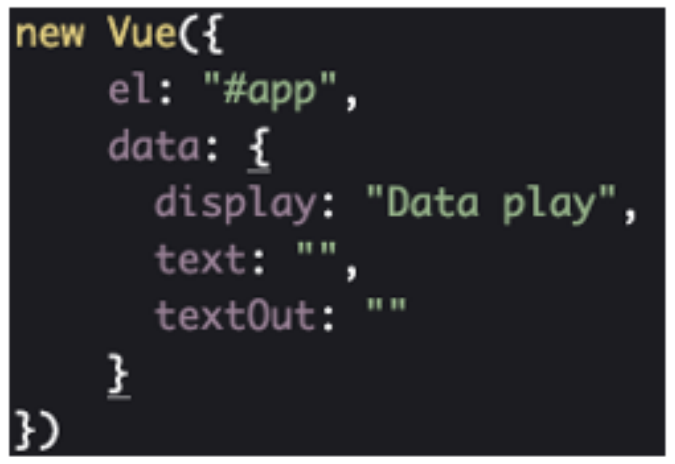

Even after this initial setup we can right now use the magic of Vue and show our display text as a title inside our document. We use a special syntax (double curly braces) to show where in the app we like to have a specific property shown. Vue will use these places and during the rendering process it adds the specific data inside of the placeholder deleting the curly braces in the process. We use h1 tags around the curly braces, with the intention of creating a header (Figure 10). With running the application, we can see, that the title appears on our display, and it has the value which we have written inside the display property of the returned object of data.

Figure 10: Displaying the title with vue. Personal collection

\section{$<\mathrm{h} 1>\{\{$ display $\}\}</ \mathrm{h} 1>$}

We add basic form to our HTML. We connect the input with our text data property using another special Vue action called a directive. The specific directive we use is the $\mathrm{v}$-model. It creates a binding between the input and the specific data property. In addition we add a directive called v-on (with the shortened syntax of (a) on the form submit (Figure 11).

This directive checks on a specific event. In our case it is the submit event. With that we will call a method (which is not written yet) called rewrite. We will write this method a bit further. The "prevent" after the submit prevents the form submit default behavior which would reload our webpage.

Now we go back to Vue and create a method property. The method (a function which is run by the computer) which we call on submit (a submit event is happening when 
Figure 11: Form with Vue directives. Personal collection

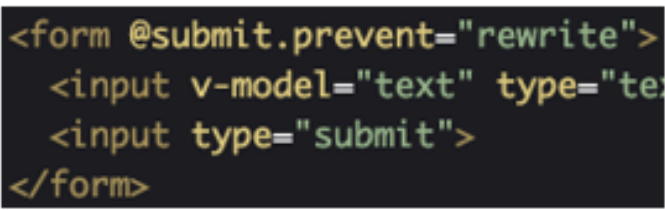

the user clicks the submit button or presses enter while writing inside the form) named rewrite (Figure 12).

It will take the text inside of the input and split it between every character. After this happens, he assigns the value to the third data property we defined in the beginning (textOut).

\section{Figure 12: Method added. Personal collection}

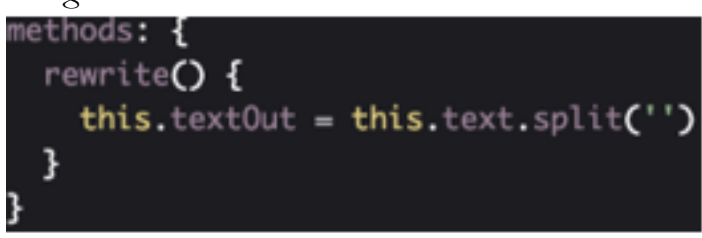

So now on our click event this method will run. We should show our textOut inside template, but first we create a computed property. It is again a special property of Vue JS which can be added to the options object of Vue instance. Properties are widely used in Vue in cases where the data changes. An example of its usage is to concatenate the first name and the last name of a person. We here use it a bit differently for the purpose of paper. It is a valid usage of it anyway even if it is not an example which we would use in practical development.
It will run on every change on input text. We create a method of the computed object called reversedText (Figure 13).

Figure 13: Added computed property. Personal collection

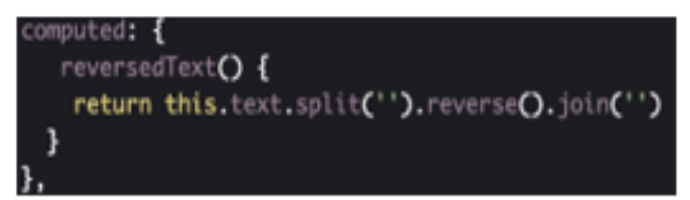

Then we used some JavaScript methods which are shipped with the String object. These do not need to be coded. It will take the text split it reverse it and joint it again together. As the last step we include these elements into the HTML of our webpage again using the above-mentioned syntax (Figure 14).

With this done our small interactive web app is done and we can check our output on the page (Figure 15). The whole project can be found here:

https://codepen.io/petkoneo/pen/QoYYJg

Figure 14: Last HTML changes. Personal collection

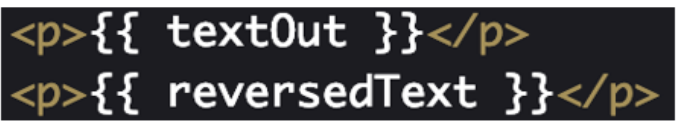


Figure 15: Final look of web app. Personal collection

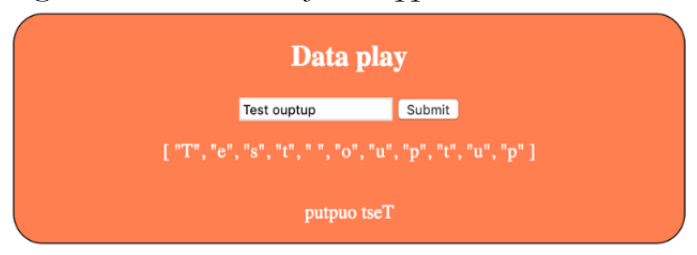

Only with 18 lines of JavaScript code we created a small interactive web app on which we can show and change data in real time. It took only 5-10 minutes to make and the code which means that even with this many totally different functionality, it can be written in a really short period of time. It is a concise and clear code and we know what does exactly what. We think that for this reason Vue JS is a good option to teach web development or to learn it.

\section{Conclusion}

In conclusion we can say, that working in Vue JS framework is straightforward and easy to understand even for the non-experienced developers. The knowledge base needed to create a basic application is not that high hence you can learn the basics really fast. It is easily usable in classes or in schools to make learning web development an easier and more interactive experience. Even if we do not intend to work in Informational Technologies, we can learn the basics of web $\mathrm{dev}$ with it and be more conscious about what is happening behind the scenes during our browsing.
Increase of IT skills in the population is one of the Slovak government and European Commission priorities for the Vision 2020 EU project. Based on the forecast from 2013 in 2020 there will be a need for 900000 IT specialist in EU, whereas around 20000 will be missing in Slovakia itself. This difference between need and offer of the EU labor market in IT is being solved by the Digital Skills and Jobs Coalition European Commission project. (Rada Vlády, 2017)Aim of our paper is to help with the IT education as the web development is known as progressive and usable part of the IT, which makes it interesting to learn.

\section{References}

Bover, P. (2018). Vue.js: the good, the meh, and the ugly - Pier Bover - Medium. Letöltés: 2019.04.14. Web: https://medium.com /@Pier/vue-js-the-good-the-meh-and-theugly-82800bbe6684

Codeburst (2019). JavaScript Trends in 2019 codeburst. Letöltés: 2019.04.14. Web: https://codeburst.io/javascript-trends2019-64042e9aa1f7

Greguš, M. and Ktyvinska, N. (2015). Service Orientation of Enterprises - Aspects, Dimensions, Technologies (Bratislava).

Kryvinska, N., Auer, L., and Strauss, C. (2011). An Approach to Extract the Business $V$ alue from $\mathrm{SO} A$ Services. In Snene, M., Ralyté, J. and Morin, J.-H. (eds.): Exploring Services Science. Berlin, Heidelberg: Springer. Kryvinska, N. and Greguš, M. (2014). SOA and its Business Value in Requirements, 
Features, Practices and Methodologies (Bratislava).

Kumar, A (2018). React vs. Angular vs. Vue.js: A

Complete Comparison Guide - DZone Web

Dev. Letöltés: 2019.04.14. Web: https://dzone.com/articles/react-vs-

angular-vs-vuejs-a-complete-comparison-gu

Landefeld, C. (2016). Key Differences Between a Website and Web App. Letöltés: 2016.02.16.

Web: https://modeeffect.com/keydifferences-between-website-web-app/

Morley, L. (2015). How Much Should a Company Spend on IT? Letöltés: 2019.04.16. Web:https://blog.techvera.com/company -it-spend

Neagoie, A. (2018). Tech Trends Showdown: React vs Angular vs Vue. Letöltés: 2018.12.10.
Web: https://medium.com/zerotomas tery/tech-trends-showdown-react-vsangular-vs-vue-61ffaf1d8706

Rouse, M. (2015). What is framework? Definition from WhatIs.com. Letöltés: 2019.04.14.

Web:

https://whatis.techtarget. com/definition/framework

Szabó, T. and Pšenáková, I. (2011). Az internetes alkalmazások biz̧tonsági biányosságai. (Nitra).

Vlády, R. (2017). INFORMATIZACLA Rada vlády SR pre digitalizáciu VS. Letöltés: 2019.04.14. Web: http://www.informa tizacia.sk/862-menu/23220s

You, E. (2019). Introduction - Vue.js.. Letöltés: 2019.04.14. Web: https://vuejs.org/v2/ guide/ 